\title{
Effect Of The Application Of Constant And Variable Temperatures at the Overaging Stage in the Mechanical Properties of Trip780 Steel
}

\author{
Rafael Ricardo Magalhães ${ }^{a} \bullet^{\infty}$, Fernando de Souza Costa ${ }^{b}$, Berenice Mendonça Gonzalez ${ }^{c}$ \\ ${ }^{a}$ Gerência Técnica de Laminação a Frio, USIMINAS, Ipatinga, MG, Brasil \\ ${ }^{b}$ Gerência de Pesquisa e Desenvolvimento de Produtos, USIMINAS, Ipatinga, MG, Brasil \\ ${ }^{c}$ Departamento de Engenharia Metalúrgica e de Materiais, Universidade Federal de \\ Minas Gerais - UFMG, Belo Horizonte, MG, Brasil
}

Received: January 30, 2019; Revised: May 24, 2019; Accepted: June 03, 2019

\begin{abstract}
The effect of the application of constant temperatures (isothermal plateau) and variables (cooling ramp) during the overaging (OA) stage of the continuous annealing cycle in the microstructural characteristics and mechanical properties of a TRIP steel of the class of $780 \mathrm{MPa}$ was investigated. It was simulated six overaging conditions in the equipment Gleeble. The microstructures presented variable fractions of ferrite, bainite, retained austenite and a small martensite portion. All the conditions achieved the minimum strength of $780 \mathrm{MPa}$ it is possible to highlight the conditions for initial OA temperature of $440{ }^{\circ} \mathrm{C}$ where presented the best results of mechanical properties and typical TRIP steels behaviors.
\end{abstract}

Keywords: Mechanical Properties, TRIP Steel, Overaging, Continuous Annealing.

\section{Introduction}

In recent years, one of the main objectives of the automotive industry is to reduce the weight of vehicles in order to reduce fuel consumption and, consequently, the emission of gases from the burning of hydrocarbons, which contribute to the greenhouse effect. In addition to caring about the environment, car safety precautions and impact resistance requirements are also part of the new vehicle concept to be developed in the next years by the automotive industry.

In order to meet all of the needs described above, the steel industries have started investing in the development of new steels technologically more advanced for application in vehicles. In this scenario, the called Advanced High Strength Steels (AHSS) were developed ${ }^{1}$.

The Transformation Induced Plasticity (TRIP) steels are characterized by superior results in terms of mechanical strength and uniform elongation, as well as higher impact energy absorption capacity compared to Dual Phase (DP) and High Strength Low Alloy (HSLA) steels with the same degree of mechanical strength ${ }^{1,2}$. On the other hand, it has the disadvantage of using a relatively high carbon content, which generally impairs the weldability of the material. Its microstructure is typically composed of polygonal ferrite (F), bainite (B) and retained austenite (RA) ${ }^{3,4}$. The retained austenite, which is a metastable constituent at room temperature, is essential for obtaining the set of mechanical properties presented by this type of steel.
It is a well documented fact that the retained austenite can become martensite by deformation ${ }^{3,4}$. This being a harder phase, there is an increase in the ultimate tensile strength (UTS) and the instantaneous strain hardening exponent " $\mathrm{n}$ " of the material. In addition, this transformation is accompanied by a volumetric expansion. These combined effects contribute to retard the mechanical instability that precedes the rupture of the material, which is reflected in an increase in the uniform elongation of the material, since its final rupture is postponed.

The production of a cold rolled TRIP steels involves the realization of an annealing cycle with heating in the intercritical field whose most important steps are those of soaking and overaging $^{5}$. At the end of the soaking stage the microstructure of the material consists of austenite and ferrite. The volume fraction of each of them depends primarily on the temperature and soaking time. During the subsequent slow cooling occurs decomposition of the austenite formed in the soaking in ferrite. In the overaging stage, bainite formation occurs. In this stage of the process, the silicon element plays the very important role of delaying the formation of cementite. For this reason, the bainite formed during overaging is carbidefree and is therefore called bainitic ferrite by many authors ${ }^{4,5}$.

The mechanical properties of TRIP steels are directly related to the type, quantity, morphology and distribution of the constituents, which, in turn, depend on the processing parameters used. Thus, in this work, the effect of initial and end temperatures on the overaging stage of the continuous 
annealing cycle on the microstructural characteristics and mechanical properties of a low-carbon TRIP steel of the 780 MPa was investigated. It was also intended to determine the best initial OA temperature condition, in terms of mechanical properties, for processing to be used in the overaging step in an industrial continuous annealing process.

\section{Materials and Methods}

In this study was utilized a C-Mn-Si TRIP steel of the class of $780 \mathrm{MPa}$ minimum strength class.

After cold rolling were taken samples of $150 \mathrm{~mm} \times 50$ $\mathrm{mm} \times 1.10 \mathrm{~mm}$ (length $\mathrm{x}$ width $\mathrm{x}$ thickness), with the largest dimension parallel to the cold rolled direction of the sheets. The samples were submitted to simulations of continuous annealing at Gleeble thermomechanical simulator. For this study, some parameters used in the simulations were fixed, based on a typical annealing cycle of the continuous industrial process. In this way, the annealing cycle was defined as Figure 1:

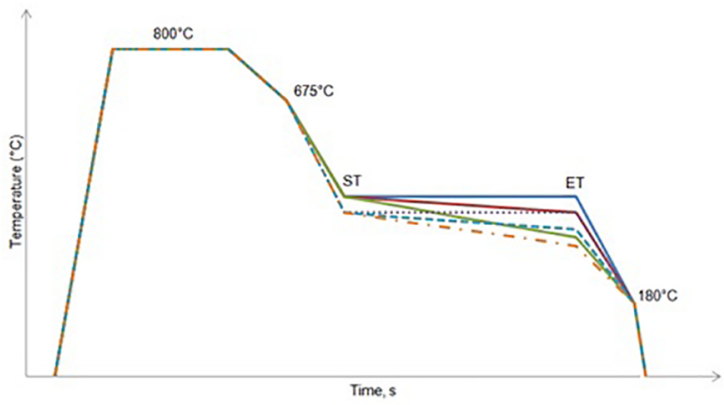

Figure 1. Schematic cycles used in the study.

- Initial heating of the samples, at a rate of $6^{\circ} \mathrm{C} / \mathrm{s}$, until reaching the temperature of $800^{\circ} \mathrm{C}$;

- Soaking the sample at a temperature of $800^{\circ} \mathrm{C}$ for $50 \mathrm{~s}$

- Cooling at a rate of $6^{\circ} \mathrm{C} / \mathrm{s}$ until reaching the temperature of $675^{\circ} \mathrm{C}$;

- Cooling at a rate of approximately $35^{\circ} \mathrm{C} / \mathrm{s}$, until reaching the temperatures of beginning of $\mathrm{OA}$.

- $\quad$ Overaging, with initial (IT) and end (ET) temperatures and cooling rates between these two temperatures as shown in Table 1;

- Cooling at a rate of $5^{\circ} \mathrm{C} / \mathrm{s}$, to the temperature of $180^{\circ} \mathrm{C}$, followed by cooling with water to room temperature.

For the analysis by scanning electron microscopy (SEM) the samples were etched with $4 \%$ nital reagent. Sections along the thickness and parallel to the rolling direction were analyzed. In order to investigate the microstructure of the samples. The sample number 4 was also submitted to EBSD analysis. Final polishing was carried out with colloidal
Table 1. Overaging conditions simulated.

\begin{tabular}{ccc}
\hline No. & Initial temperature $\left({ }^{\circ} \mathrm{C}\right)$ & End temperature $\left({ }^{\circ} \mathrm{C}\right)$ \\
\hline 1 & & 440 \\
2 & 440 & 400 \\
3 & & 360 \\
\hline 4 & & 400 \\
5 & 400 & 360 \\
6 & & 320 \\
\hline
\end{tabular}

silica after the conventional metallographic preparation. The EBSD data were acquired at a voltage of $20 \mathrm{KV}$ and step size of $150 \mathrm{~nm}$.

The volume fraction of retained austenite and its carbon content was measured by X-ray diffraction using Co-Ka radiation. The retained austenite fraction dosage was carried out applying the Rietveld method. The carbon content of the austenite, in turn, was obtained from the intensity of the plane (220)g. The austenite fraction was also determined as a function of the plastic deformation in the samples 4 and 6 submitted to deformation ranging from $5 \%$ to $25 \%$.

The tensile tests were performed according to ASTM A370-11, $2011^{6}$. The total elongation (measuring base equal to $25 \mathrm{~mm}$ ), yield strength (at $0.2 \%$ deformation) and ultimate tensile strength were determined through tensile test on subsize test bodies.

\section{Results}

\subsection{Mechanical properties}

The mechanical properties after the different simulated conditions in Gleeble are shown in Table 2.

Figure 2 illustrates the yield strength (YS) behavior for the different strategies of performing the overaging stage.

The ultimate tensile strength results are illustrated in Figure 3 in which it can be seen that all conditions obtained UTS higher than $780 \mathrm{MPa}$. The condition 6 had the higher UTS. This increase is directly related to the increase of the second phase content in the microstructure obtained under these conditions.

In Figure 4 are shown the results of total elongation (TE) of the simulated conditions. Among them it is possible to emphasize the condition 1 and 2 with total elongation of $39 \%$.

In Figure 5 the balance between resistance and total elongation, of the simulated conditions, presented results that varied between 26 and $34 \mathrm{GPa} \%$. It was possible to highlight the conditions that used $440{ }^{\circ} \mathrm{C}$ at initial $\mathrm{OA}$ temperature, it obtained the best results. These values are well above other high strength steels such as Dual Phase (UTS $=900$ $\mathrm{MPa}, \mathrm{UTSxTE}=11.6 \mathrm{GPa} \%$ ) and Bainitic (UTS $=650 \mathrm{MPa}$, UTSxTE $=8.0 \mathrm{GPa} \%$ ) and are aligned with TRIP multiphase steels, as shown in the studies by Sugimoto et al. ${ }^{7}$ 
Table 2. Mechanical properties of TRIP780 steel obtained under various OA conditions.

\begin{tabular}{ccccccccccc}
\hline No. & Initial $\left({ }^{\circ} \mathrm{C}\right)$ & End $\left({ }^{\circ} \mathrm{C}\right)$ & \multicolumn{2}{c}{ YS $(\mathrm{MPa})$} & \multicolumn{2}{c}{ UTS $(\mathrm{MPa})$} & \multicolumn{2}{c}{ TE $(\%)$} & \multicolumn{2}{c}{$\mathrm{n}$} \\
\hline 1 & 440 & 440 & $488 \pm$ & 5 & $875 \pm$ & 11 & $39 \pm$ & 1 & $0.30 \pm$ & 0.00 \\
2 & 440 & 400 & $484 \pm$ & 3 & $837 \pm$ & 8 & $39 \pm$ & 1 & $0.26 \pm$ & 0.01 \\
3 & 440 & 360 & $483 \pm$ & 3 & $847 \pm$ & 3 & $36 \pm$ & 1 & $0.25 \pm$ & 0.00 \\
4 & 400 & 400 & $476 \pm$ & 8 & $841 \pm$ & 3 & $36 \pm$ & 1 & $0.23 \pm$ & 0.00 \\
5 & 400 & 360 & $453 \pm$ & 7 & $854 \pm$ & 1 & $31 \pm$ & 1 & $0.23 \pm$ & 0.00 \\
6 & 400 & 320 & $427 \pm$ & 5 & $912 \pm$ & 12 & $28 \pm$ & 1 & $0.24 \pm$ & 0.01 \\
\hline
\end{tabular}

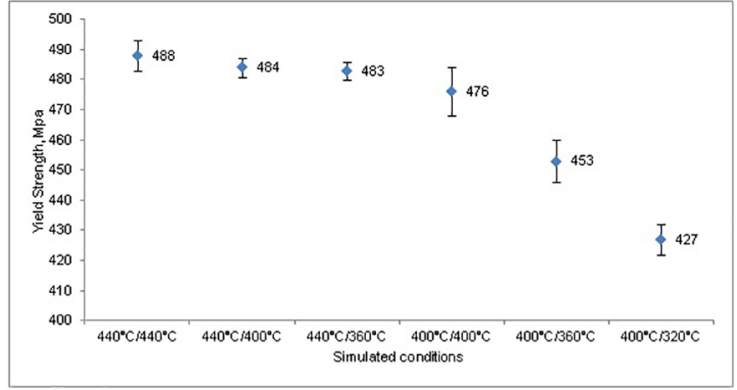

Figure 2. Yield strength of simulated conditions.

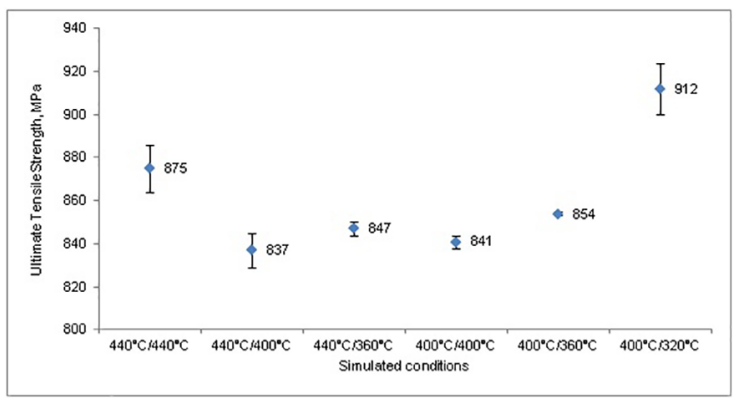

Figure 3. Ultimate tensile strength of simulated conditions.

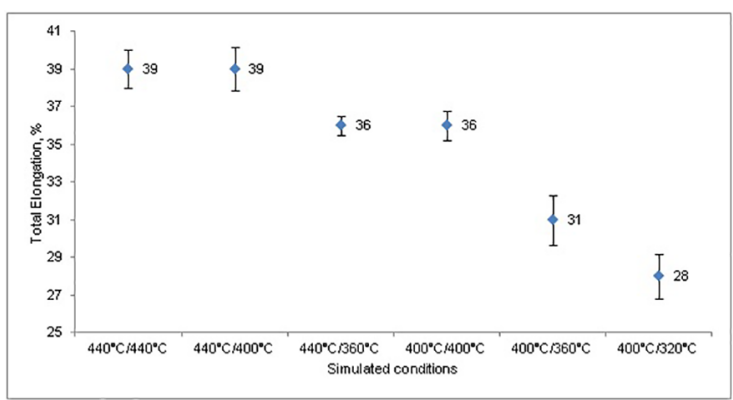

Figure 4. Total elongation of simulated conditions.

In Figures 6 are illustrated the stain hardening exponent results in function of true strain to the 6 conditions tested. The conditions presented typical strain hardening exponent curves of TRIP steels according to Xiong et al. ${ }^{8}$, except the condition 6 .

\subsection{Microstructure}

The steel studied after different annealing process was analyzed in a scanning electron microscopy SEM. The

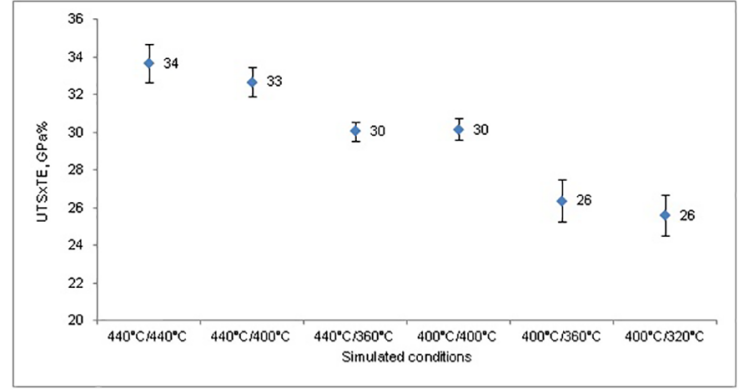

Figure 5. Balance between strength and total elongation of simulated conditions.

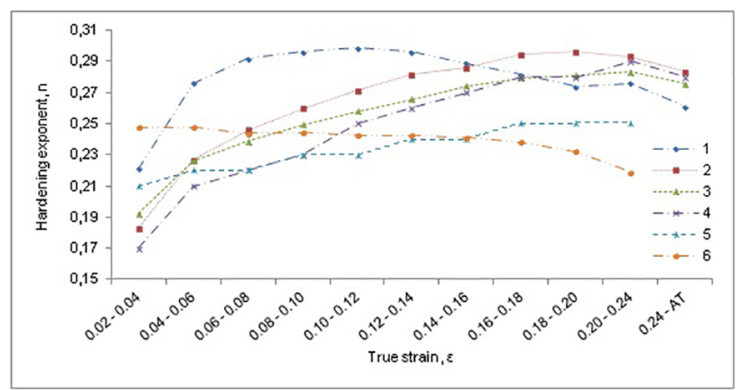

Figure 6. Instant strain hardening exponent for studied conditions.

microstructure observed was of ferrite, bainite, retained austenite and a little martensite portion. Only the last condition (no. 6) visually showed increased presence of second phase in the microstructure, as shown in Figure 7.

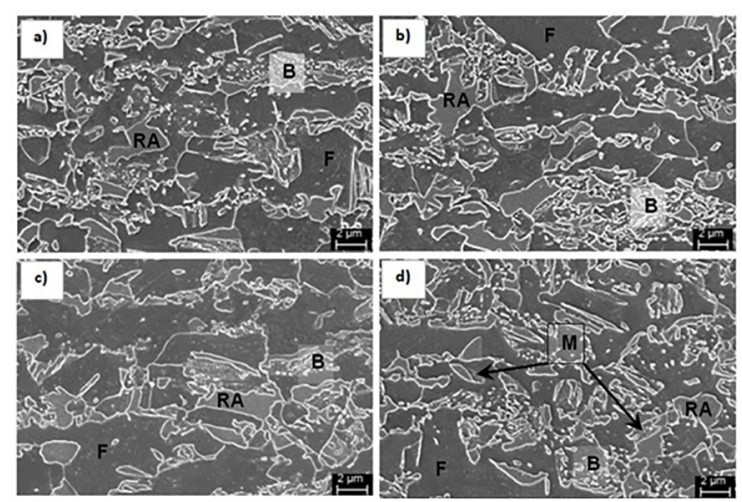

Figure 7. Scanning electron microscopy of TRIP780 at isothermal temperature conditions (a) 1, (c) 4 and non-isothermal conditions (b) 3, (d) 6 . 
The EBSD of the sample processed according condition 4 was used to construct band slope and phase maps, which are are shown in Figure 8. In the phase map the CCC-like structures are colored in red and the retained austenite (FCC) is highlighted in blue.

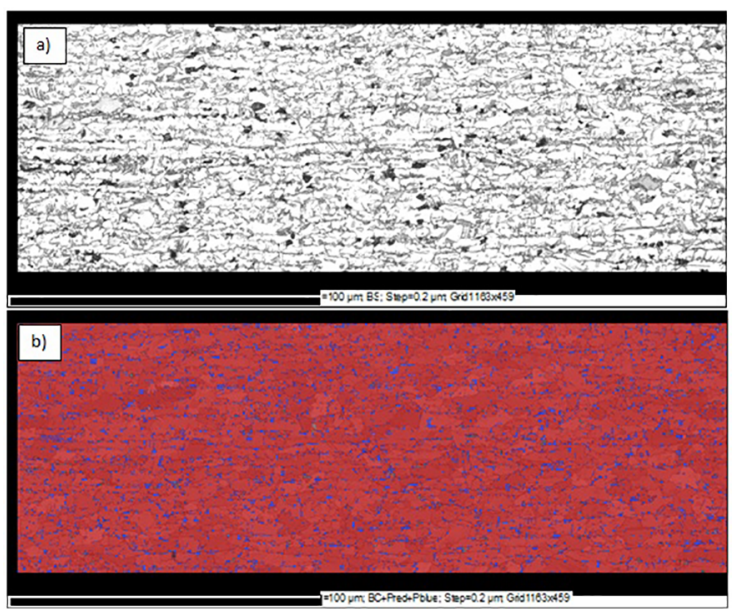

Figure 8. BS map (a) and Phase map (b) of the sample processed with isothermal plateau of $400^{\circ} \mathrm{C}$ (condition 4). Austenite retained is highlighted in blue.

In order to differentiate ferrite and bainite phases, a separation method proposed by Kwon et al. ${ }^{11}$. The authors attributed all the highest value counts in the BS scale, 255, to the ferritic phase and the measurements below that value were assigned to the bainitic phase.

The pixels identified with FCC type structure, colored blue in figure 8 (b), were attributed to the retained austenite. On the other hand, as mentioned, the pixels of the CCC structure, with band slope values lower than 255 , were attributed to bainite. The obtained results are shown in Table 3 .

Table 3. Results of the phases present in the microstructure of the sample processed with isothermal plateau of $400^{\circ} \mathrm{C}$ (sample 4).

\begin{tabular}{cccc}
\hline \multirow{2}{*}{ Sample 4 } & \multicolumn{3}{c}{ Microstructure statistics (\%) } \\
\cline { 2 - 4 } & Ferrite & Bainite & $\begin{array}{c}\text { Retained } \\
\text { Austenite }\end{array}$ \\
\hline $400^{\circ} \mathrm{C}$ overaging & 50,2 & 39,9 & 9,9 \\
\hline
\end{tabular}

Since the ferrite formation occurs at higher temperatures than those applied at the overaging stage in this work, the ferrite fraction of the six samples evaluated can be considered to be close to $50 \%$.

The results of the volumetric fraction of retained austenite and its carbon content, obtained by X-ray diffraction, are shown in Table 4.

$\mathrm{X}$-ray diffraction measurements presented retained austenite values higher than that obtained by EBSD. This can be explained by the difficulty of detecting the retained
Table 4. Retained austenite fraction and its carbon content. Measurements carried out by X-ray diffraction.

\begin{tabular}{ccc}
\hline No. & $\begin{array}{c}\text { Retained Austenite } \\
(\%)\end{array}$ & $\mathrm{C} \gamma(\% \mathrm{w} / \mathrm{w})$ \\
\hline 1 & 15,2 & 1,18 \\
2 & 16,0 & 1,17 \\
3 & 14,5 & 1,14 \\
4 & 15,8 & 1,20 \\
5 & 15,0 & 1,09 \\
6 & 14,9 & 1,05 \\
\hline
\end{tabular}

austenite between lath of bainite by EBSD. Normally with this technique is possible to detect blocky austenite.

The retained austenite fraction values as a function of the plastic deformation applied in samples 4 and 6 are shown graphically in Figure 9.

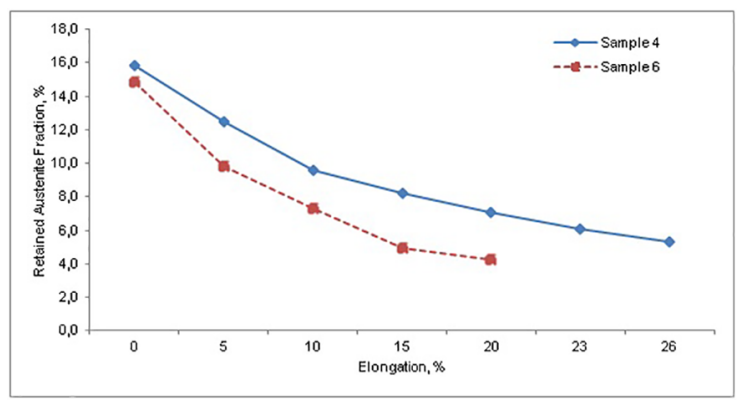

Figure 9. Retained austenite fraction values as a function of the plastic deformation applied in samples 4 and 6 .

\section{Discussion}

In all conditions for $440{ }^{\circ} \mathrm{C}$ initial temperature presented mechanical properties and typical TRIP steels behaviors. This can be explained by the microstructure and capacity of increase of the hardening exponent is gradual, corresponding to the successive transformation of the retained austenite ${ }^{5,8,9}$. For the other conditions, there was a drop in the yield strength results with the decrease of the final OA temperature. The YS is controlled by the ferrite formed before overaging stage. It is plausible to suppose that the decrease in the temperature of end OA has favored the formation of a greater amount of free discordances in the ferrite. This hypothesis, however, could only be confirmed by transmission electron microscopy analysis by, which could not be accomplished in this study.

Difference results of mechanical properties obtained in this study can be explained by the small by relative variations in the fractions of bainite, retained austenite and its carbon content between the different samples. In addition, sample 6 also showed a small amount of martensite. In this way, this sample presented a set of properties slightly similar to that of a Dual Phase steel. Wang et al. ${ }^{5}$ commented in their studies that the ferrite content is important in TRIP steels, 
because the matrix, in the transformation-induced processing, the ferrite readily absorbs the volumetric expansion of the retained austenite for the transformation of the martensite with complementary paper for the TRIP effect. Sakuma et al. ${ }^{10}$ stated that a good plasticity of the TRIP steel should be the result for the tension induced transformation of the interaction of the matrix phase ferrite and retained austenite. Thus, an appropriate amount of ferrite and a large number of RA are a prerequisite for good plasticity of TRIP steels.

\section{Conclusion}

1. For the conditions simulated the microstructure were basically constituted by ferrite, bainite, retained austenite and a small percentage of martensite.

2. All the conditions achieved the minimum strength of $780 \mathrm{MPa}$ it is possible to highlight the conditions for initial OA temperature of $440{ }^{\circ} \mathrm{C}$ where presented the best results of mechanical properties and typical TRIP steels behaviors.

3. The use of low OA temperatures, associated with variable temperature, was not effective for the production of TRIP780 steel.

\section{Acknowledgements}

The authors wish to thank the National Council for Scientific and Technological Development (CNPQ), Brazil, for their financial support, and USIMINAS for permanent technical support of this research.

\section{References}

1. Kuziak R, Kawalla R, Waengler S. Advanced high strength steels for automotive industry. Archives of Civil and Mechanical Engineering. 2008;8(2):103-117.
2. Bhargava M, Tewari A, Mishra SK. Forming limit diagram of Advanced High Strength Steels (AHSS) based on strain-path diagram. Materials \& Design. 2015;85:149-155.

3. El Mehtedi M, Spinarelli S, Zrnik J. Effect of thermomechanical processing on the microstructure of Si-Mn TRIP steel. La Metallurgia Italiana. 2010;10:5-10.

4. Kim SJ, Lee CG, Choi I, Lee S. Effects of heat treatment and alloying elements on the microstructures and mechanical properties of $0.15 \mathrm{wt}$ pet $\mathrm{C}$ transformation-induced plasticityaided cold-rolled steel sheets. Metallurgical and Materials Transactions A. 2001;32(3):505-514.

5. Wang LH, Tang D, Jiang HT, Liu JB, Chen Y. Effects of Continuous Annealing Process on Microstructures and Properties of C-Mn-Si Bearing Cold-Rolled TRIP Steel. Advanced Materials Research. 2013;602-604:472-477.

6. ASTM International. ASTM A370-11 - Standard Test Methods and Definitions for Mechanical Testing of Steel Products. West Conshohocken: ASTM International; 2011.

7. Sugimoto K, Usui N, Kobayashi M, Hashimoto S. Influences of Temperature and Strain Rate on Ductility in TRIP Aided Dual-Phase Steels. ISIJ International. 1992;32(12):1311-1318.

8. Xiong ZP, Kostryzhev AG, Chen L, Pereloma EV. Microstructure and mechanical properties of strip cast TRIP steel subjected to thermo-mechanical simulation. Materials Science and Engineering: A. 2016;677:356-366.

9. Dan WJ, Li SH, Zhang WG, Lin ZQ. The effect of strain-induced martensitic transformation on mechanical properties of TRIP steel. Materials \& Design. 2008;29(3):604-612.

10. Sakuma Y, Matsumura O, Akisue O. Influence of C Content and Annealing Temperature on Microstructure and Mechanical Properties of $400^{\circ} \mathrm{C}$ Transformed Steel Containing Retained Austenite. ISIJ International. 1991;31(11):1348-1353.

11. Kwon EP, Fujieda S, Shinoda K, Suzuki S. Characterization of transformed and deformed microstructures in transformation induced plasticity steels using electron backscattering diffraction. Materials Science and Engineering: A. 2011;528(15):5007-5017. 